\title{
Qualitative doctoral research in educational settings: Reflecting on meaningful encounters
}

\author{
Myria Pieridou', Maria Kambouri-Danos ${ }^{2}$ \\ ${ }^{1}$ School of Education, Childhood, Youth and Sport Education, The Open University, UK \\ ${ }^{2}$ Institute of Education, University of Reading, UK
}

\section{Article Info \\ Article history: \\ Received Oct 15, 2019 \\ Revised Jan 12, 2020 \\ Accepted Feb 14, 2020 \\ Keywords: \\ Doctorate research Early career research Qualitative methodology Reflection Research in schools}

\begin{abstract}
In qualitative doctoral research the methodological approach, and the research design are extremely important when ensuring the rigorousness of the work. This is particularly significant for all researchers, and even more for doctoral students who are still developing their research and analytical skills. This paper aims to support doctoral students in their research journey by highlighting some of the tensions involved in conducting qualitative research by unpicking the experiences of two doctoral students to learn from the concerns, questions and reflections on the use of qualitative methodology in their doctoral research projects. The findings reveal challenges and insights with regards to reflection, educational research and the developing identity of being a researcher. The paper discusses these reflections to support and guide doctoral students as early career researchers when planning and conducting qualitative research in educational settings.
\end{abstract}

This is an open access article under the CC BY-SA license.

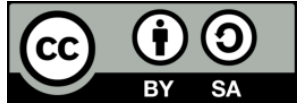

\section{Corresponding Author:}

Maria Kambouri-Danos, Institute of Education, University of Reading, 4 Redlands Road, Reading, RG1 5EX, UK.

Email: m.danos@reading.ac.uk

\section{INTRODUCTION}

Most researchers are inextricably involved in the research process and their choices undeniably influence their interpretation [1,2] as they bear personal values and biases, and preconceptions about the context and the participants [3-5]. More specifically, several decisions are made throughout the research process, from the research questions asked, to the way findings are presented [6,7], and these may be planned or spontaneous, conscious or subconscious [3]. Thus, it is important for researchers to be cognisant of the fact that they are part of the social world being researched, as this would encourage them to become more reflective during the all research stages [8]. It is, therefore, important for each researcher to communicate and write in a way that makes visible the self and the reasons for engaging in the research process. Allowing a dynamic self-awareness process to be developed [5], can make the personal and/ or social contextualisation affecting the research more explicit. As a result, this dynamic process contributes to the understanding of the knowledge and limitations of the study.

Doctoral students face many challenges during their studies, therefore this paper uses reflection to discuss the experiences of doctoral students in education and the use of qualitative methodology in order to provide support to other doctoral student facing similar issues. To do that we focus on two encounters that were noted during two exploratory research projects, conducted as part of each authors' doctoral studies. The studies shared a common interest in exploring phenomena in the educational context and were conducted in mainstream educational settings. Other common elements between the two studies included their research 
methods, as well as the emphasis placed on researcher-participants relationships, reflection and ethical issues. The first one investigated the inclusion of seven children with disabilities in mainstream primary schools, through a careful examination of the enactment of the 113(I)/99 Special Education, which legislated the inclusion of pupils with special needs into mainstream settings. Main areas of investigation were the functioning of the special units, and the collaboration between mainstream and special teachers and parents of children with disabilities [9]. The research methodology included interviews, observations, reflective diary and document and legislation analysis. The second project investigated the ways in which pre-primary teachers responded to young children's scientific misconceptions and aimed to provide guidance to teachers on this topic [10]. This research focuses on teachers working in public and private kindergartens, and children attending these kindergartens, aged from three to five and a half years old. The research methodology included interviews, observations, focus groups and document analysis. Following the advice of her supervisors, the doctoral student also keep a reflective diary, extracts from which she often shared with the supervisors during meetings in order to unpick some of the journey's challenges.

The two authors met briefly at a conference during their doctorates and were then found to be working together at a university based in the UK. Through several conversations, they were able to identify that, despite the different topic and focus of their studies, they both encountered challenges and through dialogical exchanges, discovered that they encountered much of the same tensions in conducting classroombased research. This paper is based on a reflective and dialogic approach between the two authors, through which the interaction between researchers and practitioners is analysed. In order to do so, two forms of 'encounters' with teacher-participants in the two research projects, conducted by the two authors, are presented, with an analysis of the challenges faced during the research process. This is contextualised by a discussion around reflective research and the challenges faced by doctorate students as early career researchers, but it is not attempted to "carry out an exhaustive analysis and assessment of this academic and practical debate" [11]. Instead, our aim is to identify and explore the tensions involved in conducting qualitative research in classrooms with teachers, especially as doctoral students and early career researchers. To put it in Oikonomidoy's and Wiest's words, the aim is "to delineate important considerations for those who are embarking on research journeys" [7].

Following an analysis of the theoretical background in relation to conducting doctoral research and the importance of reflection, the chosen methodology for the research projects and their common ground is outlined [1], and subsequently the encounters identified with the teacher-participants are presented. In this paper the researchers attempt to reflectively study their own research practices [12], to examine their interpersonal relationships with the teacher-participants and to understand their reactions and everyday praxis. The encounters identified describe common moments in both research journeys and include examples of establishing relationships of trust with teacher-participants. The paper offers an insight to other doctoral students facing similar challenges and can help them to unpick and reflect on their own studies.

Educational research demands the employment of different sets of relationships with the research field and other researchers which are affected by a set of value-laden concerns about individual, community and societal well-being [13, 14]. When claiming that the objective of the research is to try to gain understandings, the participation of the people affected most by a social situation is essential. Educational research can aim to explore, interpret and/or critically examine the situation under investigation [15]. The literature highlights that qualitative research studies all have "...a common epistemological ground: the researcher determination to minimize the distance and separateness of researcher-participant relationships," [16].

In this paper, we explore the doctoral educational research process and its challenges through the eyes of two early career researchers to identify common encounters that were important during the research process. To do this, reflection was used which allowed to look back at the research process and the decisions made during all the research stages and consider if those choices were appropriate or whether there could be a better way to conduct the research or to respond to certain situations [17]. Reflection is seen as the process of examining the ways in which the researchers' identities are involved in constructing interactions, understandings and meaning making throughout the data collection and analysis process. This results in the acknowledgement of the researchers' interpretation of portraying the social world [Vernon 1997 quoted in 3, 5]. As Elliot, Ryan and Hollway [18] explain, reflection is used as a means to understand data that is embodied, unspoken or hidden from consciousness.

In effect, reflection allows the doctoral researcher to challenge interpretations of the world that sustain and/or reinforce power relations, but at the same time the risk of it constituting structures of inequality and discrimination, is acknowledged, as only the researchers' voice of reflection is heard [1]. Within the educational research projects discussed here, reflection helped to critically engage with the research process as it offered a way to challenge hierarchical relationships with the participants and its primary importance is to acknowledge emotion and reactions on behalf of the researchers in the two 
projects [19, 20]. Reflection's 'fragmented, dynamic and partial' characteristics are embraced and are interpreted as features 'of its success and importance' [1].

Slee [21] noted that reflection is "a requirement rather than an option for researchers", which is encouraged by Fox and Allan's [1] argument that reflection allows to address the tension between the researchers' set of assumptions and points of view and the practical realisation of the project. Through the reflective process, the notion of the value-neutral researcher is challenged, because it places as a more critical view on the researcher, his/her background, views and values, and suggests a more hermeneutic approach towards understanding the research process [3]). This means that emphasis is placed not only on what is done, but how it is done [17], something which can be seen as a strength of the study, because it increases the trustworthiness of research. To do so, researchers have acknowledged and in-depth engagement with ethical issues and dilemmas, understanding of the power relationships with the participants, and can recognise, problematise and reflect on issues around access and trust.

Considering the above, reflection is a key aspect of the doctorate ride and a big part of an early career's researcher's journey, as it helps the early career researcher to navigate through different encounters. As Walker and Thomson [22] note, one of the biggest challenges of doctorate students is to grow in confidence and discernment into their scholarly and critical identities. This is possible because the journey of becoming a professional researcher requires doctoral researchers to reflect, negotiate new identities and redefine themselves both as people and professionals, in addition to learning specific skills [23].

In addition, doctoral students in education, such as the authors of this paper, have the advantage of a solid commitment to education which is usually complemented by some professional experience as well. As Labaree [24] discusses, this commitment to education translates into a sense of to improve schools and education in general. Thus, any potential issues that doctoral students in education would face, are not because they lack commitment, experience, or maturity but according to Labaree [24] they usually relate to potential cultural conflicts, referring to the nature of teaching practice and the nature of educational research as a practice. In this paper, we examine these conflicts and unpick them in more depth, aiming to identify the tensions involved in conducting qualitative research in classrooms with teachers.

Ethics, the ethics of care and the impact the research projects may have on participants is an important part of reflection [4], especially since each research situation generates different ethical issues in all aspects of educational research, which demands unique answers [3, 25]. Most educational researchers are also affected from a certain set of moral codes developed based on their individual values and beliefs. In both research projects, a considerable amount of time was devoted reflecting on ethics, which also helped to maintain professional trust and credibility [4]. Moreover, ethics and reflection are important in the consideration of power relations and the dynamics between researcher(s) and participant(s), which often result in asymmetries in the research process and influence the nature of data collected [25]. Variations in the dynamics of the interactions between the researchers and the participants impact the nature of the collected data and may have lasting effects on participants. Furthermore, power dynamics also influence the presentation and dissemination of results, as the researchers have the 'power' or 'ability' to select or dismiss particular views by the participants' (Rinke and Mawhinney 2014), subject to their own biases and perspectives. In effect, researchers have a moral obligation to not cause any harm to the participants or exploit their trust, and also to recognise their own and the participants' willingness to share personal responses and/or emotional reactions $[4,26]$.

Consequently, it is important to consider power relations and how research might affect others and scrutinize these as a key part of the ethical process. This should always be done on a case-by-case basis and with careful thinking and attention to specific details and circumstances [25]. In the projects discussed in this paper, the topics of access, establishing relationships of trust, and maintaining a balanced relationship with the participants were carefully considered [7, 9]. For example, the researchers valued and appreciated the participants' views and experiences in both projects during group discussions and interviews, by responding with appropriate follow up questions, asking for examples, and actively listening to their perspectives. Furthermore, the researchers engaged in a reflective analysis of the ethical dimension after the completion of the projects, so as to analyse the consequences on participants and themselves.

Finally, ethics in research concern ethical guidelines and procedures. In Cyprus, as well as in other countries such as Britain, educational researchers conform to the ethical procedures specified by recognised associations, such as the British Education Research Association (BERA), as well as the guidance given on educational research and academic research by the specific institution involved, and the country's Ministry of Education. Taking this into consideration, both research projects ensured that informed consent, confidentiality and anonymity were applied [27]. Participants were aware of the aims and methodology chosen to conduct the research projects, while pseudonyms were used to safeguard their identity. The aim of both projects was to present and understand participants' views in their own context and shed light in areas with limited research in Cyprus, and not to stigmatise particular schools or teachers. 


\section{RESEARCH METHOD}

The main research question aimed to identify the tensions involved in conducting qualitative research in classrooms with teachers, especially as doctoral students and early career researchers. To support this explorative process, the methodology chosen to recollect the research journeys for the two projects did not seek to capture a single truth but involved an approach through which researchers' re-examined meaningful interactions between themselves and the participants. The first phase involved reviewing the methodology used for each project, and finding the common ground and differences, whereas the second phase focused on identifying the researcher-participant relationships aiming to identify common encounters in the two projects. Thereafter, a dialogic approach that would allow researchers to share their reflections and comment on them, without seeking to capture absolute truths, was employed [1]. The challenging and complicated nature of the research journeys was acknowledged, through documenting thoughts and dilemmas related to the identified encounters with teachers-participants in the course of a series of exchange of emails.

To clarify the context of both projects, which were the doctoral studies of the researchers, and to provide a general understanding of their main similarities and differences, the methods employed in each study, are synoptically presented here. The first project examined the enactment of the 113(I)/99 Special Education law in Cyprus, which legislated the inclusion of children with disabilities in mainstream settings, mainly with regards to the functioning of special units in mainstream schools, the use of differentiated methods by teachers, and teacher-parent collaboration. It is worth noting that children with disabilities in that particular context were placed in a special unit, a rather standard practice after the passing of the 113(I)/99 Law, where they received individualised support, or support in small groups by special teachers, while they were also partially included in mainstream classrooms $[9,28]$. The implementation of the current legislation was examined through an in-depth qualitative research, by conducting a case study in a mainstream primary school. An initial critical analysis of the 113(I)/99 law took place, while the data collection was conducted with observation of seven children with disabilities for three months, followed by semi-structured interviews with the head-teacher of the specific school, the special and mainstream teachers (total of fourteen teachers), the teacher assistants and the parents of the children with disabilities.

The aim of the second project was to examine teachers' understandings and children's preconceptions when teaching science [29]. The data for this project was mainly collected through face to face interviews and two focus groups interviews. Eleven pre-primary teachers, who were working with children between three and five years old, took part in the study. In addition, eleven science lessons were observed to watch the same teachers 'in action' along with a document analysis of the national curriculum and the main science handbook available to the teachers at the time. In both projects, the distance from the teacher-participants, in a professional dimension, was reduced due to the researchers' existing teaching experience and background at the time of data collection.

\subsection{Research design}

During the realisation of their doctoral projects, both authors/researchers kept a reflective journal which included notes with regards to the research methods employed, specific comments on the participants' reaction and collaboration, as well as personal thoughts and dilemmas during the whole process [27]. These notes, in some cases, acted as a first level of analysis of main data and allowed researchers to move "beyond simple recollection to deeper level of reflective action" [1]. The reflective journals initiated the dialogic approach between the two researchers which developed to a methodical review of the data included in the diaries [27]. The two researchers conducted numerous meetings throughout an extensive period (one academic year) and developed a number of reflections focusing on both positive, as well as challenging memories and incidents documented in the journals.

Overall, this analytical attempt led to the development of a broader knowledge base, since it helped to establish information and examples of common encounters emerging through the researchers' interactions with the teacher-participants. The role of other key agents in the research process, such as the first and secondary doctoral thesis supervisors, ethics committee, and administrative officials involved, was also noted in this process. However, the focus in this paper remains on teacher-participants and on the more challenging encounters with them, as these are considered to have the potential to be more meaningful and benefit other doctoral students and early career researchers.

The development of the encounters with teacher-participants focuses on the tensions of the relationships between researchers and the teachers and the attempt to understand where these tensions were deriving from. The aetiology for choosing to reflect on the encounters considered to be challenging came as recognition of the complexity in the research process and the effort in maintaining a balanced relationship with teacher-participants. Furthermore, this has the potential to engage other researchers in a much-needed dialogue regarding reflection within different types of research relationships. The encounters 
described and discussed here are concerned with behaviour, attitudes and views of teacher-participants and were defined as the 'I am not liable' teacher and the 'uncomfortable' teacher.

\title{
3. RESULTS AND DISCUSSION
}

The results are presented and discussed simultaneously, due to word limitations. The discussion is based on the reflective process that the two authors went to in order to answer the research questions in relation to identifying common encounters that were important during the research process. Revisiting the data collected from both projects during the interviews and the observations, with a focus on the researchers' reflective journal notes, as well as extracts from the researchers' dialogic approach supported the reflective process used to answer the research questions. The encounters that were identified are presented below and will be contextualised with examples from each research project.

\subsection{The 'I am not Liable' teacher}

One of the first things noticed as a common characteristic in both projects, was the tendency of teacher-participants to be more reluctant into taking responsibility for differentiating their lessons. In the first project, data analysis indicated that several teachers defined inclusive education in a way that allowed them not to be considered 'liable' for the education of children with disabilities. During interviews with the mainstream teachers, they appeared to interpret their role with regards to inclusion in relation to two factors; informing children without disability about inclusion (three teachers) and differentiating their lesson (seven teachers), factors, also, supported by Blecker and Boakes [30] and Kourea and Phtiaka [31] as being important in inclusive education. In this case, differentiation can be seen as a means towards inclusive education, as it is a pedagogic strategy which entails the adjustment of learning activities, sources and routines, in a way that enables all children to participate and learn [32]. More particularly, it can be concerned with the differentiation of content, approach, instructions, and assessment during lessons [33].

Nevertheless, observations indicated that despite this verbal support towards inclusive education and differentiation, teachers still showed low expectations towards children with disabilities and did not systematically differentiate their lessons. The findings showed that out of the forty teaching periods each child was observed in mainstream classrooms, only $10 \%$ included differentiated activities, materials, and/ or assessment processes, which is also documented by Pieridou [9], Phtiaka [34] and Phtiaka, Michalidou, Tsouris and Vlami [35] in the Cypriot context. As indicated in the reflective journal:

\begin{abstract}
"After one month of observation, it appears that teachers do not prepare adequately for children with disabilities. I think they tend to forget, rather than not care, though sometimes I'm not sure. They often stated the phrase 'I am not liable' for this or that, or for this child, and therefore they justify their lack of preparation. I hear them say, almost every day, that these children's teacher is the special teacher alone." (Journal Entry, 5/11).
\end{abstract}

An example of the lack of differentiation was the vice-head teacher's teaching practices during the process of electing a student council for her classroom. The observation analysis showed that two students with disabilities were not given the opportunity to be candidates for the classroom's council and were also not allowed to vote for other students. Field-notes showed that this decision was not based on characteristics of the children's educational needs, as both children had very good oral and good written communication and could bring about the task of taking part in the classroom elections. Even though both children were physically included in the mainstream classroom during the elections period (two learning periods), they were passive participants. After the two learning periods, an informal discussion took place with the vice-head teacher, as it was evident that she wanted to explain her decision, while the researcher was also eager to understand the vice-head teacher's actions. According to the field notes of that day, the vicehead teacher argued that her decision was towards the best interest of the children, so that she would not hurt or stigmatise them in front of their peers, as she believed they were not capable to participate on their own. Based on this assumption, she decided that their characteristics were responsible for their exclusion, something which indicates her views around ability and disability and her understandings on the value of diversity in mixed ability classes [35].

When this was discussed again during the interview, the vice-head teacher stated that the special teacher was informed and agreed with the process she followed. More particularly, according to the vicehead teacher: 
"I talked with the special teacher, and she told me that she, too, preferred they wouldn't take part in the elections, because they didn't know their classmates' names and surnames, as there are synonymies. Nor were they in a place to choose a few boys or girls. Their bulletins would be void... (If they didn't follow the rules). And we didn't want them to be disappointed because they wouldn't be able to complete the bulletin. They can take part in the next elections. We left it so we wouldn't create them extra problems, so they wouldn't feel bad. (...) You see, it's not my responsibility, the special teacher can have other elections in the special unit with them, her students". (Interview: Vice headteacher)

The event described above was a turning point for the specific project, as it became evident that even though all teachers verbally accepted inclusion as a concept, they generally considered that it was not part of their responsibility to realise it. Unfortunately, the vice-head teacher's behaviour to avoid taking responsibility for the two children with disabilities included in her classroom was documented on a number of occasions (field-notes 6/10, 26/10, 10/11). Observation also showed that other mainstream teachers often used various excuses to avoid taking responsibility for the educational and social development of children with disabilities. Some that were often used were: "children are included simply by being in the classroom, I don't need to do much" (Interview, Music Teacher), "the curriculum is too stressful to deal with differentiation, as well. No matter how much one wants to help it's impossible" (Key Stage 3 teacher), "we can't manage to do everything. We have our children (without disabilities) to deal with" (Interview, Teacher Key Stage 2). These show the teachers' limited knowledge in terms of inclusion and inclusive practices, which according to Slee [36] and Liasidou [37] are viewed as a set of values and pedagogic principles that aim for the enablement of marginalised learners and the identification and removal of barriers for their participation and success. Furthermore, teachers' statements also indicate the lack of cooperation with the special teacher, who could have acted as a mediator for inclusion by providing valuable information to mainstream teachers [9].

The involved researcher experienced a range of emotions during the teacher's statements and behaviour, which were documented in her reflective journal. This was due to the researcher's difference of perspective and her engagement with notions of inclusion, equality and social justice for a number of years during her studies and research activities. In effect, the researcher's theoretical knowledge and empirical background led her to interpret in a particular way teachers' praxis, especially when children with disabilities were not given opportunities to participate and succeed in inclusive environments [33, 35]. In one of her reflective journal entries, after the incident described earlier with the vice-head teacher, the researcher noted:

"I think the trouble with the vice-head teacher is her lack of awareness on the consequences of her actions... She genuinely felt that her praxis were appropriate given children's weaknesses and disabilities, yet observation shows that children could have participated in their classroom's elections. I wish I could do something... Should I discuss this further with her? Am I part of the system that perpetuates exclusion if I don't?"' (Journal Entry, 6/10).

The above questions existed almost throughout the duration of the project and can only be characterised as troubling. The supervisor's role was important in these events, as numerous discussions took place with her to resolve emerging feelings and dilemmas (Journal Entry, 15/10). The supervisor helped to acknowledge the anxieties about the research journey and the data that was emerging [18]. The main dilemma was whether inclusive and discriminatory practices should be discussed with the teachers, but after numerous supervision meetings it was decided not to take any action, so as not to jeopardize access in the school environment and influence what would normally take place [9]. The decision to not take an immediate stance towards teaching practices that could potentially hinder children's educational process was a difficult decision to make, during an uneasy research process, as it adjoined personal notions and beliefs, as well as ethical issues in educational research [18, 38]. At the same time, it became clear that it was necessitated to investigate and attempt to understand why teachers often neglected differentiating their lessons, which would benefit children with and without disabilities. This led to an analysis of the primary education system in Cyprus, and towards a documentation of the gaps that leave teachers feeling unprepared and uncomfortable, with limited knowledge on the topic of inclusive education [7, 39].

Similarly, some of the teachers that participated in the second project thought that they were not the ones responsible to help children re-shape their preconceptions and construct their scientific knowledge [29]. Based on the teachers' responses, "children in the pre-primary schools are too young and they will learn more science when they will move to primary school" (Interview: Teacher 1), which has to do with 
the teachers' understanding of the general aim of the pre-primary school. Three of the teachers agreed that the aim of pre-primary education is to help and guide the children to develop their skills (e.g. observation skills) and not to change or correct their erroneous preconceptions. One of the teachers stated:

"Children use their imagination and we cannot take their right to imagine because it is a characteristic of their age. When they grow up, they will understand what is correct. It depends on how mature they are. The main aim of the pre-primary school is not to change these concepts; they will come back to them at primary school and high school." (Interview Transcription: Teacher 5).

A different teacher came to agree with the above and said, "I think that pre-primary education is more about helping children to use their imagination and it is not a main aim to eliminate their preconceptions". However, within the current national curriculum for pre-primary science is seen as a central part of children's overall development and as a means to satisfy children's need for experimentation, play and pro-active participation. The mismatch between the curriculum and statutory requirements and the views that the teachers were expressing cause a lot of confusion and frustration to the doctoral researcher who was not sure how to respond to the situation. As she notes in her journal:

\begin{abstract}
"It is challenging to have a conversation with the teachers about science when they do not really believe in the benefits of teaching science in the pre-primary school. It is difficult to think where this discrepancy is coming from (between curriculum and teacher's beliefs); it might be a lack of awareness of the curriculum and statutory requirements, even though it is most probably a lack of confidence in actually delivering science which is then justified by saying that "we don't have to do it now, they are too young, they will learn it later" (Journal Entry, 4/11).
\end{abstract}

The curriculum provides a number of learning goals from which one is "developing conceptual understanding" [40]. This indicates teachers' ignorance of what is required from them as pre-primary teachers and their preference to believe that they are not liable for children's conceptual development. Instead, the participants were eager to demonstrate their belief that future teachers were responsible to support children develop their scientific understanding, and not them.

As a result, based on both projects the researchers' concluded that behind teachers' practices and behaviours there are complex issues to be investigated. Teachers had developed their practices based on their own understandings of what could be defined as 'good', 'effective', and/or 'appropriate' for their classes, and did not seem to reflect on their assumptions and attitudes. It is also identified that the educational system in the specific context lacks in promoting evidence-based practices in schools, as well as providing teachertraining services which are relevant and accessible to all teachers. As mentioned in one of the entries in the dialogic approach followed by the two researchers during the investigation of teacher encounters:

"There is always more than meets the eye. It is true that teachers' praxis often frustrated me during my research. Nevertheless, it is a big step to wonder: 'why is this so?', instead of blaming teachers who, as they stated on numerous occasions in both projects, are 'at the front-line' and face a lot of challenges. They feel they are neglected, alone and unsupported. I think that they are, often, right." (Journal Entry, 8/11)

This has been documented by Phtiaka [34] and Angelides [41] in the Cypriot context, who stated that the centralised curriculum and the demanding nature of its structure hinders teachers from being creative, and also limits their time for differentiating their teaching and practices. Of course, this does not mean that all of the teachers' practices are justifiable, yet some can be understandable. Nevertheless, both mainstream and special teachers need to acknowledge this and try to collaborate and differentiate their lessons, in order to achieve quality inclusion for all learners.

\title{
3.2. The 'Uncomfortable' teacher
}

This encounter refers to teacher-participants who were documented as not feeling comfortable during observation, teaching, and/or interviews. During the first project, some mainstream and special teachers were noted as feeling or expressing discomfort during the research project, particularly during the first month of observation. In order to address any initial concerns of the teacher-participants and build trusting relationships with them [7], the researcher had individual discussions regarding the research topic 
and the methodology with them. Nevertheless, teacher-participants had different reactions; eight mainstream teachers welcomed the researcher into their classrooms without hesitation, while four felt more uncomfortable with her presence. More specifically, the majority of mainstream teachers felt comfortable with the researcher's presence in the mainstream classroom and conducted their lessons without being distracted. This group of teachers did not regard the researcher's role as intimidating and seemed to appreciate the necessity for conducting this project. Their positive views and ease with regards to conducting research in mainstream settings possibly came as a result of their young age, combined with the fact that the majority of them (five out of eight) had completed a postgraduate degree and had carried out research studies themselves. Consequently, they were particularly receptive in the realisation of the project.

Two mainstream teachers, however, dealt with the researcher with some reservations. The threemonth observation and numerous personal discussions with them revealed that they felt insecure regarding teaching children with disabilities. Their insecurity emerged as they worried about the lack of differentiated activities and the absence of appropriate materials, and therefore approached the researcher during or after their lessons to 'apologise' for factors that excluded children. Even though both teachers seemed to be aware of this, they did not make an effort to overcome barriers to children's participation and considered that the lack of teacher training and the demanding nature of mainstream curricula were 'to blame'. These parameters have been documented in the literature [39, 42] as factors that hinder inclusion; yet the teachers' lack of action raises concerns about their attitudes and the quality of the current inclusion of children with disabilities in mainstream settings.

As far as the special teachers and assistant teachers are concerned, they faced the researcher with some hesitation. During the first few weeks numerous occasions were noted in the reflective journal when the assistant teachers approached the researcher and were eager to be further informed concerning the observation notes. One special teacher made the same request several times, as she wanted to know specifically "what was observed and investigated" (Journal Entry, 23/09). The researcher responded to all of the participants' questions and showed the structure of the observation sheet, which included designated space for describing events per forty-minute periods, and indications for the use of differentiated teaching methods, the behaviour of children with and without disabilities, and a column to be subsequently used for data coding. It was noted that teachers were relieved by the acceptance in sharing the observation sheet with them and became more comfortable over the course of time spent in the special units. Any other concern they might have felt gradually subsided after a few weeks, as they did not identify the researcher as an evaluator of their work, because observation time was divided between the mainstream classrooms and the special units. These allowed for the special teachers to feel more comfortable and conduct their lessons without paying much attention to the researcher's presence.

The second project examined teachers' response to children's preconceptions when teaching science; to do this it was important for the researcher to focus on a single science topic in order to observe a lesson that would evolve around similar objectives and scientific concepts $[29,40]$. The first topic that was identified as the one in which children have the most preconceptions in was 'Electricity'. Thus, the researcher approached the teachers whose lessons were going to be observed and requested them to teach something in relation to this topic. However, more than half of the teachers denied teaching this topic. The same happened with the second topic that the researcher suggested, which was 'Light and Shadows' until ending up the 'Water Cycle' which was a topic that all teachers agreed to teach. The episodes described above led to the creation of challenging feelings such as anxiety, uncertainty and stress. The involved researcher faced the dilemma of what was appropriate or inappropriate to do.

\begin{abstract}
"It looks like it will be more difficult than I thought to observe teachers while teaching one of these topics. However, I am confident that the data will be rich regardless the topic selected. Nonetheless, teachers' refusal to teach these topics creates a lot of questions. Why are they so uncomfortable, or even scared? What is the reason for their lack of confidence and most importantly how can I help them? Is it my place to help them or should I just focus on my study? I need to follow this up." (Journal Entry, 15/02).
\end{abstract}

Several discussions took place between the researcher and the first supervisor focusing on this issue which aided the researcher manage feelings and respond appropriately. In this case, the supervisors enabled the research to process the information and to consider what the teachers' reaction might mean [18]. It was also important for the researcher to further investigate this during the interviews, which gave an opportunity to identify the participants' reasons to consciously avoid teaching specific topics. One of them specifically said "I feel that I do not know these topics well, I have never tried to teach them. Maybe because I didn't study science at high school, I feel that I don't have enough knowledge or the necessary materials to teach 
these topics". Similarly, Hastie and Saunders [43] suggest that the lack of the necessary equipment can significantly affect teaching and learning. However, a different teacher stated that "I've never taught "Electricity" so far because I don't feel confident and, since we are free to choose what to teach, I avoid it". Two additional teachers admitted that they felt uncomfortable teaching several topics including 'Electricity' and 'Shadows and Light'. Specifically, one of them said that "I would avoid "Light and Shadows" because I don't usually have enough time to teach it and I'm a bit scared because I'm not familiar with these topics". Similarly, another teacher stated that "I've never taught these topics because I'm a bit scared to try them. I would not feel comfortable teaching something that I don't know that well". The school's headteacher confessed that she had worked with teachers in the past that felt uncomfortable or unconfident to teach some specific topics.

It is worth noting that during both projects, teachers appeared to be uncomfortable with the idea of being observed while teaching, indicating some signs of anxiety [44]. This anxiety suggests the presence of some negative feeling, which, according to Hastie and Saunders [43] usually relate to lack of confidence because of different reasons such as lack of knowledge, time or appropriate equipment. For example, teachers tend to worry about not being able to answer all the children's questions and some might find this even more challenging or embarrassing in the presence of an observer, in this case the researcher. Even though it is normal if teachers cannot fully respond to all questions addressed by children, it is important for them to acquire the necessary knowledge for areas included in the curricula, feel comfortable when teaching, and be confident enough to differentiate their techniques and practices, in order to accommodate the needs of all children $[45,46]$.

Going back to the Labaree [24], the above encounters demonstrate two examples of the clash between the nature of teaching practice and the nature of educational research as a practice, as it is evident that the doctoral students in education, who are usually also teachers, and the teachers working within the school context, have different views, perceptions and expectations, which can lead to a cultural clash. Neumann, Pallas and Peterson [47], identify three tensions that relate to this cultural clash, including "the tension of perspective, which considers the ways in which the understanding of educational phenomena flows from the academic disciplines and from educators... and the tension of response (and responsibility) to primary stakeholders in the education enterprise, which examines the interplay of researchers' public and intellectual stakes in the study of educational phenomena." (p. 251). The third is the tension of agenda and whose questions get asked: researchers' or practitioners'. This, in combination with the commitment to education and the sense of a mission to improve schools that the doctoral researchers in education feel, occasionally leave the early career researchers feeling that they might not be doing enough. Therefore, the support and encouragement that doctoral students get from the supervisors (and later on from more experienced colleagues) is essential during the doctoral journey as it helps the young researcher to stay grounded and to navigate through different tensions and dilemmas [48].

\section{CONCLUSION}

This paper has presented some of the tensions involved in conducting qualitative research in classrooms with teachers, based on the experiences of the authors and what they identified through a reflective process. The paper has explored these tensions and how they were managed, which can help other doctoral students or early career researchers when facing with similar challenges. The encounters presented and discussed here can be considered as examples to encourage researchers to think reflectively about their responses to similar situations in analogous research journeys. Nevertheless, dilemmas and tensions encountered during qualitative research need to be carefully thought in relation to the context of the study and those involved. The results highlight that by acknowledging the role of power dynamics and emotions in the multifaceted relationship between researcher - participants, and the role of reflection in doing so, researchers can become more responsive to the role they play throughout the life of their research projects.

The review of the literature and the recognition of the researchers' unique values, characteristics, beliefs, and experiences while undertaking research, emphasised, from the offset of the two projects, the importance of continuous critical and reflective thinking. The reflective, dynamic and dialogic process meant that the two authors were distanced from their own perspectives and were, also, aware of the participants' differing reactions, identified as 'encounters'. The aim of this paper was not to propose final responses and/or solutions to the ongoing debates on conducting educational research, but to draw attention to a topic that undeniably concerns early career researchers. The aim was to share the unexpected emotional rollercoaster faced during the research process, and to place emphasis on the importance of the researchers' role when managing this as well as the importance of recognising the participants' needs and worries when conducting research. Within the paper, presenting and discussing the researchers' encounters with 
teacher-participants helped to emphasise the value of recognising the difficulties that both face during research activities.

Another important dimension to be considered is the researchers' role after the completion of the research project. Even though this has not been discussed in this paper, this could be the focus of future discussions and investigations, as it is important to draw the attention towards reflections on the use and contributions of research findings. Drawing on earlier discussions on the power dynamics between the researcher and the participants, it is suggested that examining more deeply the nature of this relationship can bring about change in the following up stage with participants. This would mean that once the project is completed the relationship with the participants would be further complemented, through sharing information, resources and key outcomes, and disseminating findings appropriately.

Therefore, the rationale, as set out in this paper, is to support the conceptualisation of reflection as an essential part of the research process, used to understand, relate to, and engage with participants and key agents during the research journey. It is suggested to treat this as a complex, non-transferrable skill that needs to be gradually developed from the outset of the research journey until, and after, its realisation. By doing so, researchers will be able to identify significant incidents that influence the process of the research project, to reflect on important discussions with the participants, and to problematise power dynamics with them. It is also suggested that the dialogic approach undertaken can inform future research practice, with regards to the planning and implementation of the research process, and with the discussion of anticipated issues that may emerge. All of these can offer essential information for a better understanding of complex and dynamic encounters with participants.

\section{REFERENCES}

[1] A. Fox and J. Allan, "Doing reflection: Moments of Unbecoming and becoming," International Journal of Research and Method in Education, vol. 3, no. 1, pp. 101-112, 2014.

[2] S. Symeonidou, "Researching disability politics: Beyond the social model and back again," in Researching disability: purpose, process and future directions, S. Symeonidou and K. Beauchamp-Pryor, Eds. London: Sense Publishers, 2013.

[3] T. N. Basit, "Ethics, reflection and access in educational research issues in intergenerational investigation," Research Papers in Education, vol. 28, no. 4, pp. 506-517, 2012.

[4] C. Costley, G. D. Elliott, and P. Gibbs, Doing work based research: approaches to enquiry for insider-researchers. London: SAGE, 2010.

[5] A. K. Hamdan, "Reflection of Discomfort in Insider-Outsider Educational Research," McGill Journal of Education, vol. 44, no. 3, pp. 377-404, 2009.

[6] M. Q. Foote and T. G. Bartell, "Pathways to equity in mathematics education: How life experiences impact researcher positionality," Educational Studies in Mathematics, vol. 78, no. 1, pp. 45-68, 2011.

[7] E. Oikonomidoy and L. R. Wiest, "Navigating cross-boundary connections in educational research," International Journal of Research \& Method in Education, vol. 40, no. 1, pp. 53-65, 2015.

[8] T. N. Basit, Conducting research in educational contexts. London: Continuum, 2010.

[9] M. Pieridou, "Special and Inclusive Education in Cyprus: Case Study of a School Unit with regards to the Implementation of the 113(I)/99 Law in Educational Practice," Ph.D Thesis, University of Cyprus, 2013.

[10] M. Kambouri, "Cypriot Early-Year Teaching of Science: Appreciation of Young Children's Preconceptions," PhD thesis, School of Education, University of Warwick, 2012.

[11] L. F. Frederiksen and S. Beck, "Caught in the crossfire: educational research in context," International Journal of Research Method in Education, vol. 33, no. 2, pp. 135-149, 2010.

[12] C. R. Rinke and L. Mawhinney, "Reconsidering rapport with urban teachers: negotiating shifting boundaries and legitimizing support," International Journal of Research \& Method in Education, vol. 37, no. 1, pp. 3-16, 2014

[13] A. Edwards, "Manual or electronic: The role of coding in qualitative data analysis," Educational Research, vol. 45, no. 2, pp. 143-154, 2002.

[14] R. K. Yin, Case Study Research Methods. California: Sage Publications, 2009.

[15] R. Tesch, Qualitative Research: analysis types and software tools. New York: Falmer, 1990.

[16] O. Karnieli-Miller, R. Strier, and L. Pessach, "Power relations in qualitative research," Qualitative Health Research, vol. 19, no. 2, pp. 279-289, 2009.

[17] A. F. Hollenbeck, "The familiar observer: seeing beyond the expected in educational research," International Journal of Research \& Method in Education, vol. 38, no. 2, pp. 149-165, 2015.

[18] H. Elliot, J. Ryan, and W. Hollway, "Research encounters, reflexivity and supervision," International Journal of Social Research Methodology, vol. 15, no. 5, pp. 433-444, 2011.

[19] M. Nind, "Inclusive research and inclusive education: why connecting them makes sense for teachers' and learners' democratic development of education," Cambridge Journal of Education, vol. 44, no. 4, pp. 525-540, 2014

[20] J. Agee, "Developing qualitative research questions: a reflective process," International Journal of Qualitative Studies in Education, vol. 22, no. 4, pp. 431-447, 2009.

[21] R. Slee, Political economy, inclusive education and teacher education. C. Forlin, Teacher Education for Inclusion: Changing Paradigms and Innovative Approaches, Eds. London: Routledge, 2010.

Int. J. Eval. \& Res. Educ. Vol. 9, No. 1, March 2020: 21 - 31 
[22] M. Walker and P. Thomson, The Routledge Doctoral Supervisor's Companion: Supporting Effective Research in Education and the Social Sciences. New York: Routledge, 2010.

[23] L. Hall and L. Burns, "Identity Development and Mentoring in Doctoral Education," Harvard Educational Review, vol. 79, no. 1, pp. 49-70, 2009.

[24] D. F. Labaree, "The Peculiar Problems of Preparing Educational Researchers," Educational Researcher, vol. 32, no. 4, pp. 13-22, 2003.

[25] P. Sikes, "On dodgy ground? Problematics and ethics in educational research," International Journal of Research Method in Education, vol. 29, no. 1, pp. 105-117, 2006.

[26] K. Tanner, "I'm crying too... help, what do I do? - Unexpected encounters experienced by a first time researcher," Current Narratives, vol. 1, pp. 69-79, 2009.

[27] L. Cohen, L. Manion, and K. Morrison, Research Methods in Education. London and New York: Routledge, 2011.

[28] S. Batsiou, E. Bebetsos, P. Panteli, and P. Antoniou, "Attitudes and intention of Greek and Cypriot primary education teachers towards teaching pupils with special educational needs in mainstream schools," International Journal of Inclusive Education, vol. 12, no. 2, pp. 201-219, 2008.

[29] M. Kambouri, "Investigating Early Years Teachers' Understanding and Response to Children's Preconceptions," European Early Childhood Education Research Journal, vol. 25, no. 3, 2015.

[30] N. S. Blecker and N. J. Boakes, "Creating a learning environment for all children: are teachers able and willing?" International Journal of Inclusive Education, vol. 14, no. 5, pp. 435-447, 2010.

[31] L. Kourea and H. Phtiaka, "The Attitudes of Students without Special Needs Towards their Integrated in the General School Classmates with Special Needs," New Education Journal, vol. 107, pp. 133-146, 2003.

[32] L. Florian, "What counts as evidence of inclusive education?" European Journal of Special Needs Education, vol. 29, no. 3, pp. 286-294, 2014.

[33] A. Broderick, H. Mehta-Parekh, and K. M. Reid, "Differentiating Instruction for Disabled Students in Inclusive Classrooms," Theory Into Practice, vo. 44, no. 3, pp. 194-202, 2005.

[34] H. Phtiaka, Educating the Other: A Journey in Cyprus Time and Space in Policy, Experience and Change, Cross Cultural reflections on Inclusive Education, L. Barton F. Armstrong, Eds. London: Springer Books, 2007.

[35] H. Phtiaka, A. Michalidou, C. Tsouris, and S. Vlami, "Evaluation of Inclusion of Children with Special Needs in the mainstream school (Primary Education)," Nicosia: University of Cyprus and Pedagogical Institute, December 2005.

[36] R. Slee, "How do we make inclusive education happen when exclusion is a political predisposition?" International Journal of Inclusive Education, vol. 17, pp. 895-907, 2013.

[37] A. Liasidou, Inclusive Education, Politics and Policymaking, London: Continuum, 2012.

[38] L. Barton and F. Armstrong, "Disability, Education and Inclusion: Cross-Cultural Issues and Dilemmas," in Handbook of Disability Studies, G.L. Albrecht, K.D. Skelman and M. Bury, Eds, London, Sage Publications, 2001.

[39] S. Symeonidou and H. Phtiaka, "My colleagues wear blinkers... If they were trained, they would understand better'. Reflections on teacher education on inclusion in Cyprus," Journal of Research in Special Educational Needs, 2012.

[40] E. Loizou and C. Papademetri-Kachrimani, Curriculum for Pre-School Education (original in Greek). Cyprus: Ministry of Education, 2011.

[41] P. Angelides, "Moving towards inclusive education in Cyprus?" International Journal for Inclusive Education, vol. 8, no. 4, pp. 407-422, 2004.

[42] K. Koutrouba, M. Vamvakari, and M. Steliou, "Factors correlated with teachers' attitudes towards the inclusion of students with special educational needs in Cyprus," European Journal of Special Needs Education, vol. 21, no. 4, pp. 381-394, 2006.

[43] P. A. Hastie and J. E. Saunders, "Effects of class size and equipment availability on student involvement in physical education," Journal of Experimental Education, vol. 59, no. 3, pp. 212-224, 1991.

[44] F. Abd-El-Khalick, "Improving science teachers' conceptions of nature of science: a critical review of the literature," International Journal of Science Education, vol. 22, no. 7, pp. 665-701, 2000.

[45] M. Bitan-Friedlandera, A. Dreyfusa, and Z. Milgromb, Z, "Types of teachers in training: The Reactions of Primary School Science Teachers when Confronted with the Task of Implementing an Innovation," Teaching and Teacher Education, vol. 20, no. 6, pp. 607-619, 2004.

[46] J. H. van Driel, D. Beijaard, and N. Verloop, "Professional development and reform in science education: the role of teachers' practical knowledge," Journal of Research in Science Teaching, vol. 38, no. 2, pp. 137-158, 2001.

[47] A. Neumann, A. M. Pallas, and P. L. Peterson, Preparing education practitioners to practice education research," in Issues in education research: Problems and possibilities, E. C. Lagemann \& L. S. Shulman, Eds. San Francisco: Jossey-Bass, pp. 247-288, 1999,

[48] D. Starke-Meyerring, "The Paradox of Writing in Doctoral Education: Student Experiences," in: Doctoral Education: Research-Based Strategies for Doctoral Students, Supervisors and Administrators, L. McAlpine and C. Amundsen, Eds. Springer, Dordrecht, 2011. 